\title{
A STUDY OF INFLUENCE OF ELECTROLYTE COMPOSITION ON ECH OF BEVEL GEARS USING MIXTURE D-OPTIMAL DESIGN
}

\author{
J. P. Misra*, P. K. Jain, D. K. Dwivedi and N. K. Mehta \\ Department of Mechanical \& Industrial Engineering, \\ Indian Institute of Technology \\ Roorkee, Roorkee 247667, India \\ Phone: +918272881586 \\ *Email: joyprakash.misra@gmail.com
}

\begin{abstract}
This paper discusses the experimental investigation to find out the optimal electrolyte composition in improving the surface quality of the gear teeth profile during surfacing finishing of bevel gears by the electrochemical honing process. In this study, AISI 1040 was used as the workpiece material, mixtures of sodium chloride and sodium nitrate in different ratios were used as the input parameter, and the percentage improvement in the surface roughness and material removal rate of the process were used as measures of process performance. The experimental runs were designed according to the Mixture DOptimal design. The analysis of the experimental outcome was carried out and $80 \%$ $\mathrm{NaCl}+20 \% \mathrm{NaNO}_{3}$ was found to be theoptimal electrolyte composition to conduct the confirmation experiments. The finding of the study establishes the process for precision finishing of bevel gears.
\end{abstract}

Keywords: Gear finishing; ECH; electrolyte; mixture design.

\section{INTRODUCTION}

Electrochemical honing $(\mathrm{ECH})$ is a hybrid micro-finishing process in which metal is removed at atomic scale by combining the action of anodic dissolution or electrolytic dissolution (i.e. electrochemical machining) and mechanical abrasion (i.e. honing). Thus, the process minimizes the shortcomings of electrochemical machining and conventional honing encountered when these processes are employed separately (ElHofi, 2005). In this research work, the process is employed to provide precision finishing to the bevel gears and thus to improve the surface quality of the gear teeth profile to improve its service performance and efficiency. The basic principle of the process is illustrated in Figure 1, in which the workpiece gear is rotated in engagement with a specially shaped cathode gear and abrasive bonded honing gear. The workpiece gear acts as a driver and the cathode gear and honing gear act as driven in the gear chain shown (Figure 1). The cathode gear is fabricated by clubbing a copper gear with a bakelite gear and undercutting the profile of the copper gear than the bakelite gear to provide an inter-electrode gap (Wiegmann \& Bube) and thus to prevent short-circuiting. The IEG is flooded with a suitable electrolyte to complete the electric circuitry in order to commence the anodic dissolution. However, during electrolytic dissolution, due to the generation of oxygen, a thin metal oxide micro-film is generated on the workpiece. This oxide layer is insulating in nature and protects the metal surface from being further electrochemically dissolved. The abrasive bonded honing gear scrubs this insulating oxide layer selectively and produces fresh metal for further anodic dissolution (Chen et 
al., 1981; Liu, Zhang, \& Chen, 2011). Very few references are available on ECH and its application for finishing internal cylinders or gears transmitting motion between parallel shafts. A brief outline of research works carried out on the ECH process is presented in Table 1. However, according to the best knowledge of the authors, no literature is presently available on ECH of bevel gears. In the present study, experimental investigation has been carried out according to the Mixture D-Optimal design to find the optimal electrolyte composition to obtain the highest percentage improvement in the surface roughness of the gear teeth profile and material removal rate (MRR) of the process.

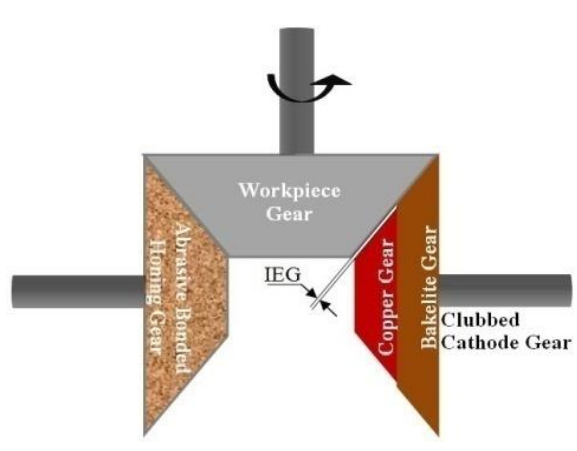

(a)

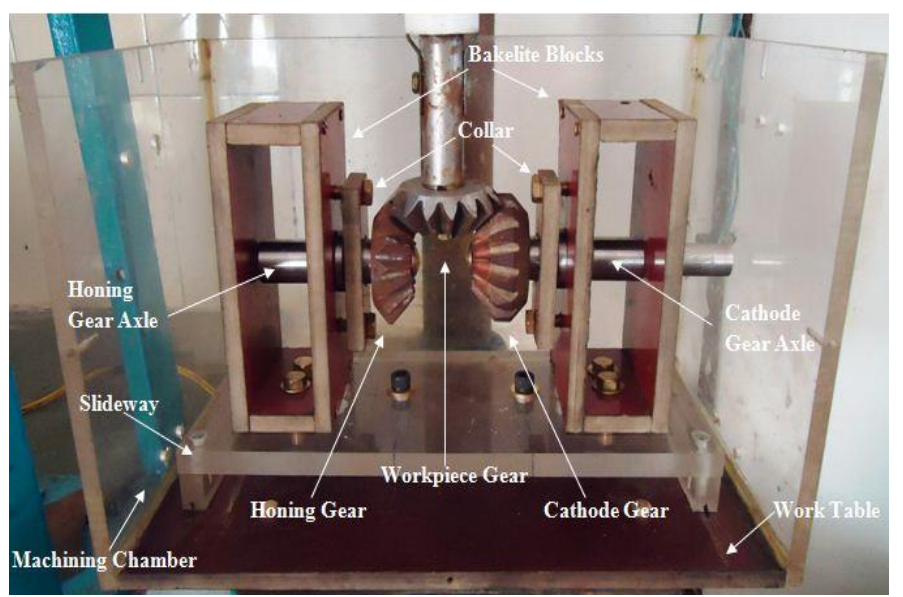

(b)

Figure 1.(a) Schematic of principle of ECH process of bevel gears; (b) photographic view of tooling system developed for ECH of bevel gears.

\section{EXPERIMENTAL SETUP}

The application of ECH for precision finishing of bevel gears has not been given due attention so far and as a consequence no such experimental setup has been reported either from the research community or from the mechanical industries. Hence, for this research work, an experimental setup with a modular tooling system has been developed. With the assistance of the modular tooling system, this setup provides the versatility of running ECH, ECM and the honing process in a single setup and is able to incorporate different sizes of gears with minimum setup changeover. The $\mathrm{ECH}$ process is associated with the power supply, electrolyte supply, and tool-motion and therefore anti-corrosiveness, electrical insulation, machinability, economic feasibility, etc. were assumed as key factors in designing and developing the machine setup. The developed setup contains four major sub-elements, namely the power supply system, electrolyte supply system, tooling and tool-motion system and machining chamber and fixtures. The power supply system consists of a 0-100 V/100A DC supplying unit that is able to operate in both continuous and pulsating mode. The positive pole of the supply is connected with the workpiece, while the negative pole is linked with the cathode gear. Carbon brush arrangements are used for supplying power to the workpiece and cathode gear. The electrolyte supply system consists of a reservoir, pump, flow meter, pressure gauges, heat exchanger, chamber drains, magnetic filters, settling tank, etc. The purpose of this sub-element is to supply the filtered electrolyte with a proper flow rate and pressure to the machining zone. The tooling and tool-motion system is the most vital 
sub-element of the setup. It consists of three types of gears: the workpiece gear; the cathode gear fabricated by clubbing a copper gear with a bakelite gear and undercutting the profile of the copper gear than the bakelite gear to provide an inter-electrode gap to prevent short-circuit; and the honing gear coated with $\mathrm{Ni}-\mathrm{Cr}$ abrasives and a DC motor to supply rotational motion to the workpiece gear. The machining chamber consists of two bakelite blocks, axles for gears, a slide way to adjust the position of the bakelite blocks and a machining chamber made of perspex to obtain a better view of the operation. The schematic diagram of the setup is demonstrated in Figure 2.

Table 1. Brief detail of past research works carried out on ECH.

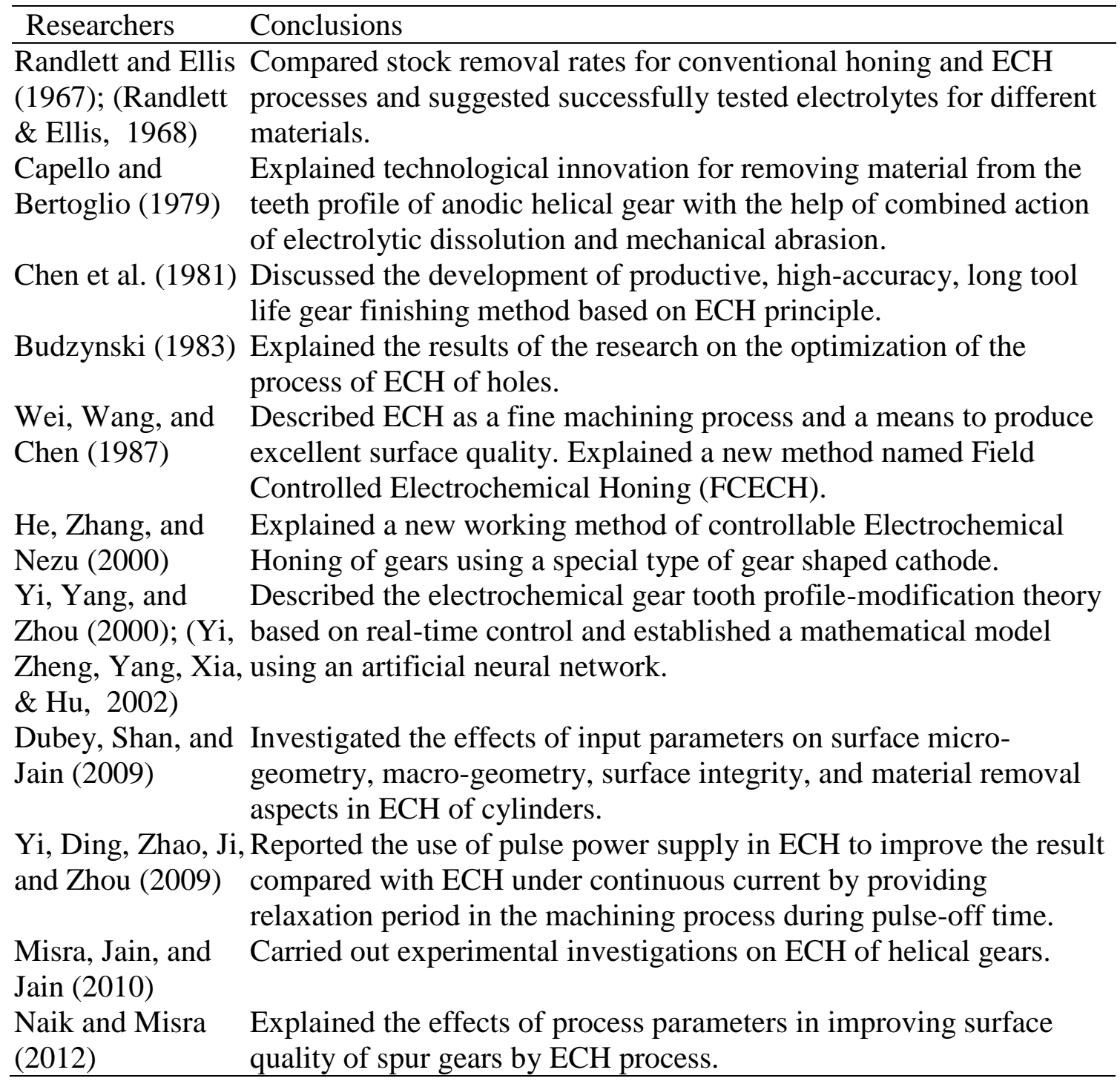




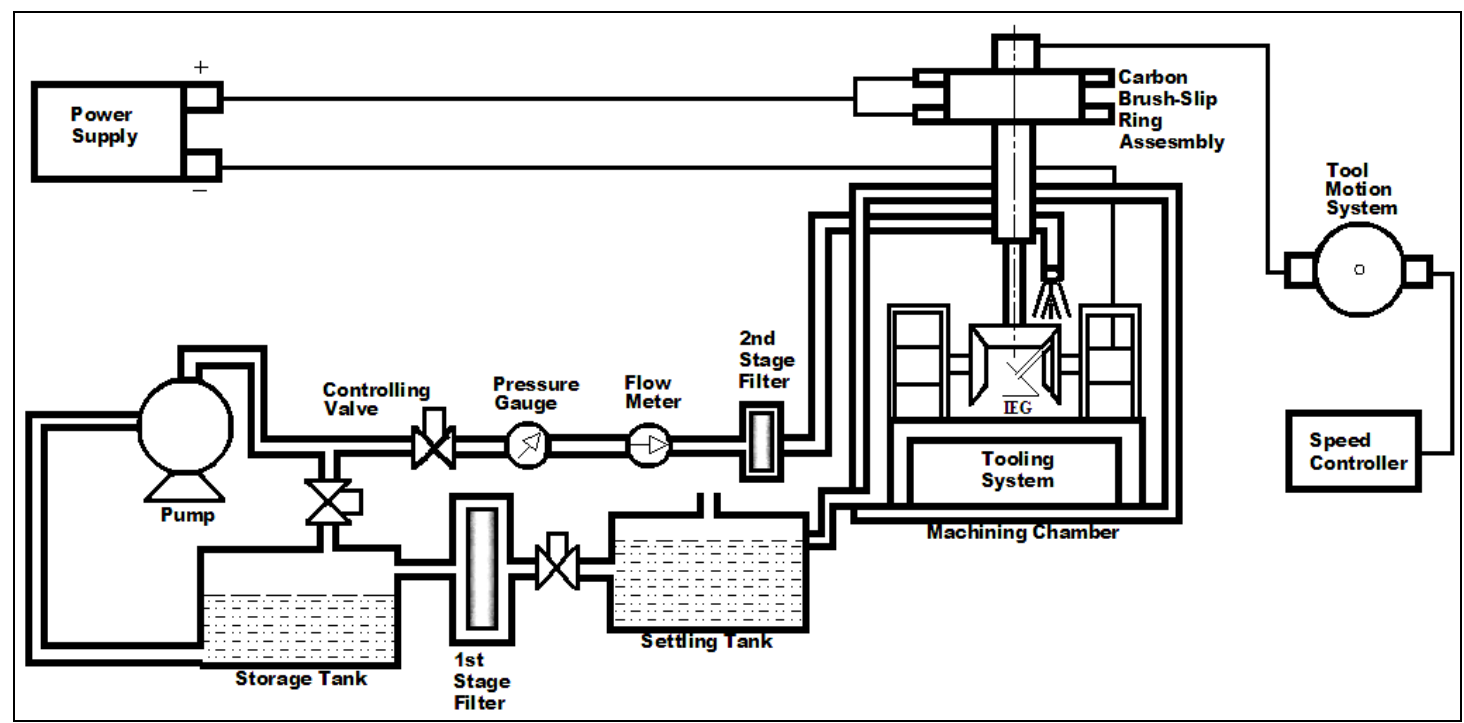

Figure 2.Schematic diagram of experimental setup for ECH of bevel gears.

\section{EXPERIMENTAL DETAILS}

\section{Workpiece and Electrolyte Selection}

In $\mathrm{ECH}$, most of the metal is removed by the electrolytic dissolution and, therefore, it is a limitation of the process that the workpiece should be conductive in nature. In this research work, AISI $1040(\mathrm{C}=0.39 \%, \mathrm{Si}=1.07 \%, \mathrm{~S}=0.71 \%, \mathrm{P}=0.75 \%, \mathrm{Fe}=$ balanced; by EDX analysis) was used as the workpiece material for its characteristics such as good machinability, easy availability, low cost, etc.In ECH, the electrolyte composition plays a crucial role as the rate of electrolysis relies on it. In the present study, mixtures of $\mathrm{NaCl}$ and $\mathrm{NaNO}_{3}$ in different ratios were used as electrolyte solution to sum up their faster material removal and better passivation effect characteristics.

\section{Experimental Procedure}

In this study, electrolyte composition was used as an input parameter while the percentage improvement in the surface roughness of the gear teeth profile and material removal rate were used as measures of process performance. The input parameters, which remained fixed for the experimentation, and their fixing criteria are presented in Table 2. In this paper, all the three most common profile roughness parameters: average, root mean square and maximum surface roughness $\left(R_{a}, R_{q}, R_{z}\right)$ were studied to get a better understanding of the process. The surface roughness values of the gear teeth profile before and after the process were captured by an optical profiler (Wyko NT 1100). The percentage improvement in surface roughness values $\left(\mathrm{PIR}_{\mathrm{a}} / \mathrm{PIR}_{\mathrm{q}} / \mathrm{PIR}_{\mathrm{z}}\right) \mathrm{was}$ quantified using Eq. (.1). 


$$
\frac{\frac{P I R_{a}}{P I R_{q}}}{P I R_{z}}=\frac{\frac{\text { Initial } \frac{R_{a}}{R_{q}} \text { Value }- \text { Final } \frac{R_{a}}{\mathrm{R}_{\mathrm{q}}} \text { Value }}{\frac{R_{z}}{R_{z}} \text { Vnitial } \frac{R_{a}}{R_{q}}} \text { Value }}{R_{z}} \times 100 \%
$$

The material removal rate of the process was calculated by Eq. (2). The mass of the workpiece before and after the process was measured using a digital weighing machine (CAS SW-LR).

$$
M R R=\frac{\text { Massof workpiece before ECH }- \text { Mass of workpiece after ECH }}{\text { Proceesing time }}
$$

Table 2. Values of input and fixed parameters used for experimentation.

\begin{tabular}{llll}
\hline Input Parameters & & \\
\hline Process parameters & Value & Levels \\
& & $\mathrm{L}_{1}$ & $\mathrm{~L}_{2}$ \\
\hline Electrolyte composition & $\mathrm{NaCl}$ & $0 \%$ & $100 \%$ \\
& $\mathrm{NaNO}_{3}$ & $0 \%$ & $100 \%$ \\
\hline Fixed Parameters & & \\
\hline Process parameters & Value & Fixing criteria \\
\hline Processing time & $10 \mathrm{~min}$ & Pilot experiments \\
Electrolyte temperature & $20{ }^{\circ} \mathrm{C}$ & Pilot experiments \\
Electrolyte pressure & $1 \mathrm{MPa}$ & Pilot experiments \\
Electrolyte flowrate & $20 \mathrm{l} / \mathrm{min}$ & Pilot experiments \\
Operation mode & $\mathrm{Continuous} \mathrm{DC}$ & Literature review \\
Current & $10 \mathrm{~A} \mathrm{DC}$ & Pilot experiments \\
Voltage & $30 \mathrm{~V}$ & Pilot experiments \\
Rotating speed & $60 \mathrm{rpm}$ & Pilot experiments \\
IEG & $0.25 \mathrm{~mm}$ & Pilot experiments \\
\hline
\end{tabular}

To evaluate the influence of electrolyte composition on the surface quality of the gear teeth profile and MRR of the process, the experimental runs were designed according to the Mixture D-Optimal design. This technique is preferred where it fulfils the following two criteria.

1. The components of the mixture add to a fixed total. This means that if the percentage of one component increases, then the percentage of other components must decrease. In short, in mixture design, the level of one factor affects the level of another factor.

2. The response parameter should be a function of the proportions of the components.

D-Optimal designs are straight optimizations based on a selected optimality criterion and the fitted model. The optimality criterion used in D-Optimal design is to maximize $\left(\mathrm{X}^{\prime} \mathrm{X}\right)$, the determinant of the information matrix $\mathrm{X}^{\prime} \mathrm{X}$. The optimization is performed to minimize the general variance of the coefficient in the model. D-Optimal 
design chooses points from the candidate point-set that are spread throughout the design region. All the points selected are model-dependent. Therefore, for an adequate design the D-Optimal points should be augmented to provide for estimation of pure error by replication and to determine the lack of fit using excess design points. In Mixture DOptimal design, the design space is defined by the low and high level constraints on each factor and any multifactor constraints (Montgomery, 2004; Stat-Ease, Inc.). In the present study, a mixture of $\mathrm{NaCl}$ and $\mathrm{NaNO}_{3}$ was used as the electrolyte composition, where the percentage amount of each salt was varied from zero to $100 \%$. The trial runs according to the Mixture D-Optimal design are presented in Table 3.

Table 3.Experimental runs and experimental results.

\begin{tabular}{lllllll}
\hline Expt. No & $\mathrm{NaCl}(\%)$ & $\mathrm{NaNO}_{3}(\%)$ & $\mathrm{PIR}_{\mathrm{a}}(\%)$ & $\mathrm{PIR}_{\mathrm{q}}(\%)$ & $\mathrm{PIR}_{\mathrm{z}}(\%)$ & $\mathrm{MRR}(\mathrm{mg} / \mathrm{min})$ \\
\hline 1 & 25.00 & 75.00 & 54.57 & 44.34 & 57.88 & 145.6 \\
2 & 100.00 & 0.00 & 60.27 & 47.39 & 62.38 & 149.3 \\
3 & 100.00 & 0.00 & 58.44 & 46.72 & 63.21 & 148.8 \\
4 & 50.00 & 50.00 & 60.83 & 48.1 & 61.33 & 147.2 \\
5 & 75.00 & 25.00 & 64.34 & 53.11 & 66.32 & 147.9 \\
6 & 50.00 & 50.00 & 61.98 & 49.25 & 63.38 & 146.9 \\
7 & 100.00 & 0.00 & 58.61 & 45.88 & 62.15 & 148.5 \\
8 & 0.00 & 100.00 & 51.66 & 41.73 & 50.12 & 143.3 \\
9 & 0.00 & 100.00 & 52.45 & 40.39 & 49.17 & 142.8 \\
\hline
\end{tabular}

\section{RESULTS AND DISCUSSION}

The experimental outcomes for $\mathrm{PIR}_{\mathrm{a}}, \mathrm{PIR}_{\mathrm{q}}, \mathrm{PIR}_{\mathrm{z}}$ and MRR are presented in Table 3. The results were analyzed and analysis of variance for response parameters was carried out using Design Expert software, as presented in Table 4. It is obvious from the analysis of variance table that the $\mathrm{p}$-values for all the models are less than 0.05 , and hence the models are significant for $95 \%$ confidence interval. Moreover, the lack of fit values are found to be insignificant. The effect of electrolyte composition on the response parameters is illustrated in Figure 3. It is evident from Figure 3 that the trend of all three roughness parameters is very similar. The $\mathrm{PIR}_{\mathrm{a}}, \mathrm{PIR}_{\mathrm{q}}, \mathrm{PIR}_{\mathrm{z}}$ values increase with the increasing percentage of $\mathrm{NaCl}$ in the electrolyte solution up to a certain level and then it starts to decrease, whereas the MRR value of the process increases with increasing percentage of $\mathrm{NaCl}$ in the electrolyte solution. This is due to the combined action of the electrolysis properties of $\mathrm{NaCl}$ and $\mathrm{NaNO}_{3}$. The rate of electrolysis depends on the number of ions present in the solution as this determines the conductivity of the electrolyte. According to the molar concentration, pure $\mathrm{NaCl}$ has a greater number of ions in solution than $\mathrm{NaNO}_{3}$. Therefore, the rate of electrolysis is higher for the $\mathrm{NaCl}$ solution but the $\mathrm{NaNO}_{3}$ electrolyte helps to produce a more uniform surface due to its better passivation effect.

\section{VALIDATION}

Parametric optimization was carried out with the help of a desirability analysis to find the optimal electrolyte composition. Using the optimal electrolyte composition (80\% $\mathrm{NaCl}+20 \% \mathrm{NaNO}_{3}$; Table 5), confirmation experiments were carried out to validate the analytical study and it was found that at optimal electrolyte composition, the process 
shows $63.11 \%$ improvement in the average surface roughness, $52.97 \%$ improvement in the root mean square surface roughness, $62.09 \%$ improvement in the maximum surface roughness and $146.78 \mathrm{mg} / \mathrm{min}$ as the MRR. The result of the confirmation experiment is presented in Table 5.

Table 4.Analysis of variance for $\mathrm{PIR}_{\mathrm{a}}, \mathrm{PIR}_{\mathrm{q}}, \mathrm{PIR}_{\mathrm{z}}$ and MRR.

\begin{tabular}{llllll}
\hline Source & Sum of Squares & Df & Mean Square & F Value & p-value \\
\hline Analysis of Variance for PIR & & & & \\
\hline Model & 149.05 & 3 & 49.68 & 74.71 & 0.0001 \\
Linear Mixture & 73.98 & 1 & 73.98 & 111.26 & 0.0001 \\
AB & 54.80 & 1 & 54.80 & 82.41 & 0.0003 \\
AB(A-B) & 17.62 & 1 & 17.62 & 26.50 & 0.0036 \\
Residual & 3.32 & 5 & 0.66 & & \\
Lack of Fit & 0.31 & 1 & 0.31 & 0.41 & 0.5581 \\
Pure Error & 3.02 & 4 & 0.75 & & \\
Cor Total & 152.38 & 8 & & & \\
\hline Analysis of Variance for PIR & & & & \\
\hline Model & 114.83 & 3 & 38.28 & 40.88 & 0.0006 \\
Linear Mixture & 47.10 & 1 & 47.10 & 50.30 & 0.0009 \\
AB & 49.10 & 1 & 49.10 & 52.44 & 0.0008 \\
AB(A-B) & 16.22 & 1 & 16.22 & 17.32 & 0.0088 \\
Residual & 4.68 & 5 & 0.94 & & \\
Lack of Fit & 1.98 & 1 & 1.98 & 2.93 & 0.1624 \\
Pure Error & 2.70 & 4 & 0.68 & & \\
Cor Total & 119.51 & 8 & & & \\
\hline Analysis of Variance for PIR & & & & \\
\hline Model & 284.18 & 2 & 142.09 & 119.85 & $<0.0001$ \\
Linear Mixture & 203.57 & 1 & 203.57 & 171.71 & $<0.0001$ \\
AB & 80.61 & 1 & 80.61 & 68.00 & 0.0002 \\
Residual & 7.11 & 6 & 1.19 & & \\
Lack of Fit & 3.94 & 2 & 1.97 & 2.48 & 0.1991 \\
Pure Error & 3.17 & 4 & 0.79 & & \\
Cor Total & 291.29 & 8 & & & \\
\hline Analysis of Variance for $M R R$ & & & & \\
\hline Model & 43.45 & 2 & 21.73 & & \\
Linear Mixture & 41.47 & 1 & 41.47 & 374.00 & $<0.0001$ \\
AB & 1.98 & 1 & 1.98 & 17.85 & 0.0055 \\
Residual & 0.67 & 6 & 0.11 & & \\
Lack of Fit & 0.17 & 2 & 0.084 & 0.68 & 0.5572 \\
Pure Error & 0.50 & 4 & 0.12 & & \\
Cor Total & 44.12 & 8 & & & \\
\hline
\end{tabular}

Table 5. Result of confirmation experiment.

\begin{tabular}{rcllllc}
\hline $\mathrm{NaCl}$ & $\mathrm{NaNO}_{3}$ & $\mathrm{PIR}_{\mathrm{a}}$ & $\mathrm{PIR}_{\mathrm{q}}$ & $\mathrm{PIR}_{\mathrm{z}}$ & MRR & Desirability \\
\hline 80.85 & 19.15 & 64.39 & 52.01 & 64.48 & 148.39 & \\
& Actual & 63.11 & 52.97 & 62.09 & 146.78 & 0.89 \\
& \% of Error & $1.99 \%$ & $1.85 \%$ & $3.71 \%$ & $1.08 \%$ & \\
\hline
\end{tabular}




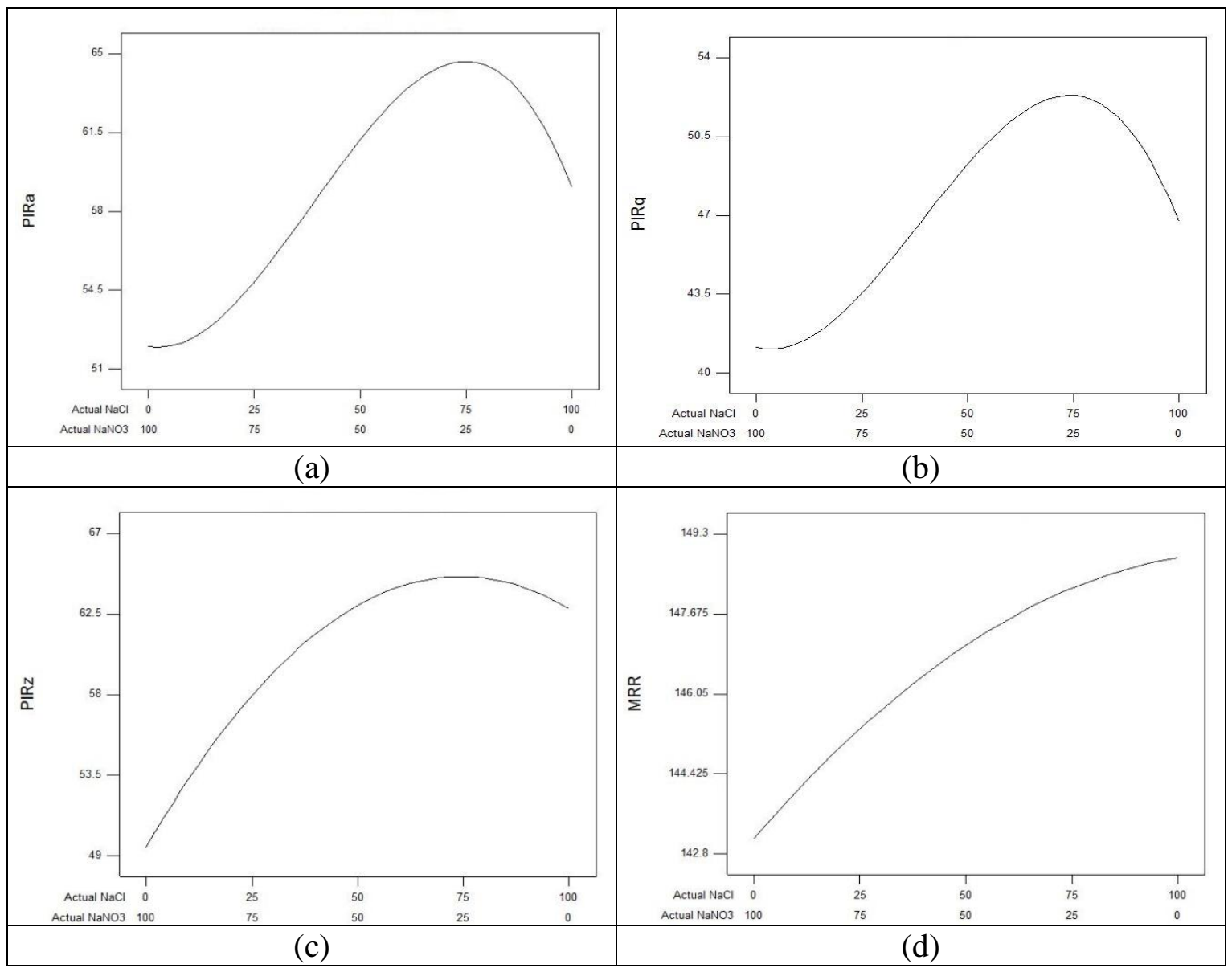

Figure 3. Effect of electrolyte composition on:(a) percentage improvement in average surface roughness; (b)percentage improvement in root mean square surface roughness; (c) percentage improvement in maximum surface roughness; and (d) material removal rate.

\section{CONCLUSION}

The present research work described the experimental investigation to explore the influence of electrolyte composition on surface quality improvement and process capability during ECH of bevel gears. The experimentation was carried out in an indigenously developed setup, and thus the study established the practicability of this setup to provide precision finishing of the complex teeth profiles of bevel gears. The research shows that electrolyte composition acts as a key factor and a proper amount of both salts is required in the electrolytic solution to enable the process to generate a uniform surface faster. The mixture of $80 \% \mathrm{NaCl}+20 \% \mathrm{NaNO}_{3}$ was found to be the optimal electrolyte composition. At this optimal electrolyte composition, the process shows $63.11 \%$ improvement in average surface roughness, $52.97 \%$ improvement in root mean square surface roughness, $62.09 \%$ improvement in maximum surface roughness and $146.78 \mathrm{mg} / \mathrm{min}$ as the MRR. Further study could consider the investigation of micro-structural and surface topographical changes to study the influence of electrolyte composition on it. 


\section{ACKNOWLEDGEMENT}

The authors wish to acknowledge the financial support obtained from DST, New Delhi, India under grant no SR/S3/MERC-0068/2010(G).

\section{REFERENCES}

Budzynski, A. F. (1983). Research on optimization of the process of electrochemical honing (ech). Paper presented at the International Symposium on Electromachining (ISEM)-7, .

Capello, G., \& Bertoglio, S. (1979). A new approach by electrochemical finishing of hardened cylindrical gear tooth face. CIRP Annals, 28(1), 103-107.

Chen, C. P., Jian, L., Guo-Chan, W., Chao-Bin, W., Jian, W., \& Lewi, R. (1981). Electro-chemical honing of gears - a new method of gear finishing. CIRP Annals - Manufacturing Technology, 30(1), 103-106.

Dubey, A. K., Shan, H. S., \& Jain, N. K. (2009). Precision microfinishing by electrochemical honing. International Journal of Manufacturing Technology and Management, 17(4), 364-372.

El-Hofi, H. (2005). Fundamentals of machining processes. New York: McGraw-Hill.

He, F., Zhang, W., \& Nezu, K. (2000). A precision machining of gears: Slow-scanning field controlled electrochemical honing. JSME International Journal Series C, 43(2), 486-491.

Liu, G. R., Zhang, G. Y., \& Chen, L. (2011). Accurate bending strength analysis of the asymmetric gear using the novel es-pim with triangular mesh. International Journal of Automotive and Mechanical Engineering, 4, 373-396.

Misra, J. P., Jain, N. K., \& Jain, P. K. (2010). Investigations on precision finishing of helical gears by electrochemical honing process. Proceedings of the Institution of Mechanical Engineers, Part B: Journal of Engineering Manufacture, 224(12), 1817-1830.

Naik, R., \& Misra, J. P. (2012). Parametric optimisation of ech of spur gears by taguchi technique. International Journal of Materials and Product Technology, 43(1), 84-101.

Randlett, E., \& Ellis, M. P. (1967). Electrochemical honing. TECH PAPER NO MR 67648, ASTME, 20501 FORD RD, DEARBORN, MICH 48128, , 1-13.

Randlett, E. A. J., \& Ellis, M. P. (1968). Electrochemical honing-ech. .

Wei, G. Q., Wang, Z. B., \& Chen, C. P. (1987). Field controlled electrochemical honing of gears. Precision engineering, 9(4), 218-221.

Wiegmann, A., \& Bube, K. (2000). The explicit-jump immersed interface method: Finite difference methods for pdes with piecewise smooth solutions. SIAM Journal on Numerical Analysis, 37(3), 827-862.

Yi, J., Ding, Y., Zhao, S., Ji, B., \& Zhou, J. (2009). A novel technique of polishing gear working surface using pecmp. International Journal of Precision Engineering and Manufacturing, 10(4), 57-62.

Yi, J., Yang, T., \& Zhou, J. (2000). New electrochemical processes gear tooth-profile modification. Manufacturing Technology and Modern Machine, 9(1), 102-105.

Yi, J., Zheng, J., Yang, T., Xia, D., \& Hu, D. (2002). Solving the control problem for electrochemical geartooth-profile modification using an artificial neural network. The International Journal of Advanced Manufacturing Technology, 19(1), 8-13. 